\title{
THE TEMPIO DELLA CONSOLAZIONE IN TODI: INTEGRATED GEOMATIC TECHNIQUES FOR A MONUMENT DESCRIPTION INCLUDING STRUCTURAL DAMAGE EVOLUTION IN TIME
}

\author{
F. Radicioni ${ }^{\text {a, } *, \text { P. Matracchi }^{\text {b }} \text {, R. Brigante }}{ }^{\text {a }}$, A. Brozzi ${ }^{\text {a }}$, M. Cecconi ${ }^{\text {a }}$, A. Stoppini ${ }^{\text {a }}$, G. Tosi $^{\text {a }}$ \\ a Dept. of Engineering (DI), University of Perugia, 06125 Perugia, Italy - fabio.radicioni @ unipg.it \\ ${ }^{\mathrm{b}}$ Dept. of Architecture (DiDA), University of Florence, 50121 Florence, Italy - pietro.matracchi@ unifi.it
}

Commission II, WG II/8

KEY WORDS: Historical Buildings, Instability and restoration of the structures, Differential Subsidence, Knowledge, Diagnostics, Laser Scanning, 3D Modeling

\begin{abstract}
:
The Tempio della Consolazione in Todi ( $16^{\text {th }}$ cent.) has always been one of the most significant symbols of the Umbrian landscape. Since the first times after its completion (1606) the structure has exhibited evidences of instability, due to foundation subsiding and/or seismic activity. Structural and geotechnical countermeasures have been undertaken on the Tempio and its surroundings from the $17^{\text {th }}$ century until recent times.

Until now a truly satisfactory analysis of the overall deformation and attitude of the building has not been performed, since the existing surveys record the overhangs of the pillars, the crack pattern or the subsidence over limited time spans. Describing the attitude of the whole church is in fact a complex operation due to the architectural character of the building, consisting of four apses (three polygonal and one semicircular) covered with half domes, which surround the central area with the large dome. The present research aims to fill the gap of knowledge with a global study based on geomatic techniques for an accurate 3D reconstruction of geometry and attitude, integrated with a historical research on damage and interventions and a geotechnical analysis.

The geomatic survey results from the integration of different techniques: GPS-GNSS for global georeferencing, laser scanning and digital photogrammetry for an accurate 3D reconstruction, high precision total station and geometric leveling for a direct survey of deformations and cracks, and for the alignment of the laser scans. The above analysis allowed to assess the dynamics of the cracks occurred in the last 25 years by a comparison with a previous survey. From the photographic colour associated to the point cloud was also possible to map the damp patches showing on the domes intrados, mapping their evolution over the last years.
\end{abstract}

\section{STRUCTURAL DAMAGE AND INTERVENTIONS ON THE MONUMENT ALONG TIME}

In the Tempio della Consolazione the problem of the restoration of the structures arose early. It should be said that this fact is not unusual in architecture for similar constructive solutions. Many possible variables are added from specific features of each construction site, as the workers capacity, the materials, the available funds, the decisions of the customer, the gradual development of design choices and, not least, the place where the building stands.

The construction of Consolazione lasted a century: the foundations began in 1508 and the dome was completed in 1607 (Bentivoglio, 1991, pp.76-87; Bruschi, 1994, pp. 514518). But by January 1638 works are already documented for the replacement of one of the four iron tie beams of the arches below the dome: the first step of the work is a supply of timber to build the necessary scaffolding. In the following March the purchase of the iron necessary for the realization of the tie beam was paid; in April 1639 are documented payments for the ropes and timber to be used for the installation of the tie beam. In the following June the new tie was put in place (Masciarelli, 1989, p. 96; Conti, 2003-04, p. 30).

It should be emphasized that for about a year and a half, a period that is not short, one of the arches below the dome was left without a tie beam. This corroborates that the pillars flanked by the tribune, even in absence of a tie, constitute a very efficient construction system to counteract the forces produced by the load of the drum and the dome.

Nevertheless, in 1653 it became necessary to replace a further tie beam, and still in 1770 a tie damaged by rust was replaced. Other tie beams were broken afterwards; in 1905 in the apse, in 1940 and again in 1959 that of the east tribune (Conti, 2004, pp. 34, 49, 112; Masciarelli, 1989, pp. 112, 116).

Within a single paper it is not possible to trace the history of the restoration works of the structures occurred over the centuries; however, some basic steps in the diagnosis and technical solutions -progressively proposed and realized- can be briefly recalled.

In 1792 Alessio Lorenzini was responsible for drawing up a comprehensive report on damage suffered by the Consolazione. Giovanni Domenico Navone junior was consulted for an opinion about the cracks that in 1794-95 opened in the walls of the southern tribuna (Comez, 1991a).

A possible link between the observed damage and the overall stability conditions of the hill was firstly glanced at by Angelo Mosconi in 1805 (Comez, 1991; Bentivoglio, 1991; Comez, 1991a).

In the drawing of Figure 1, it is shown the profile of the slope along the direction N-S down to the Naja river. The original drawing indicates some areas of local shallow instabilities (properly dilamazioni in originary Italian - Comez, 1991), as well as the area at the foot of the slope, involving the cliff above the river. A proposal for intervention is also represented 
in the drawing, which shows the section of a massive wall to be built on the south side of the church.

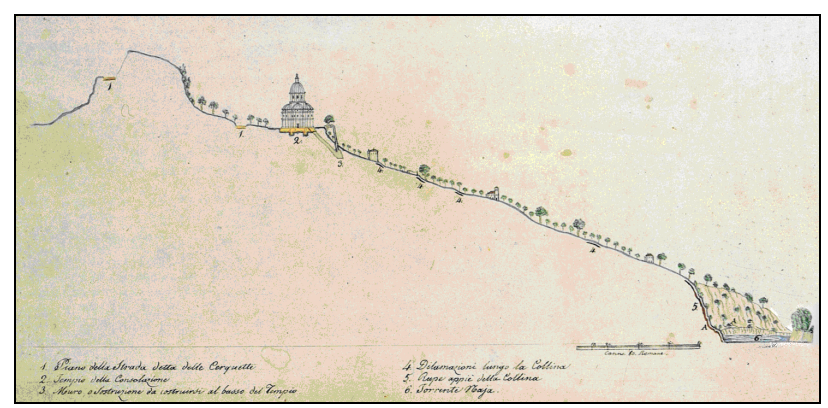

Figure 1

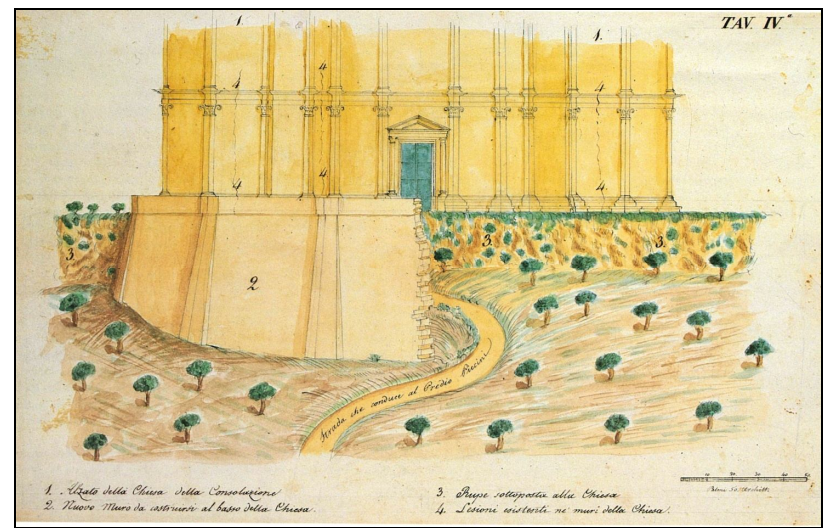

Figure 2

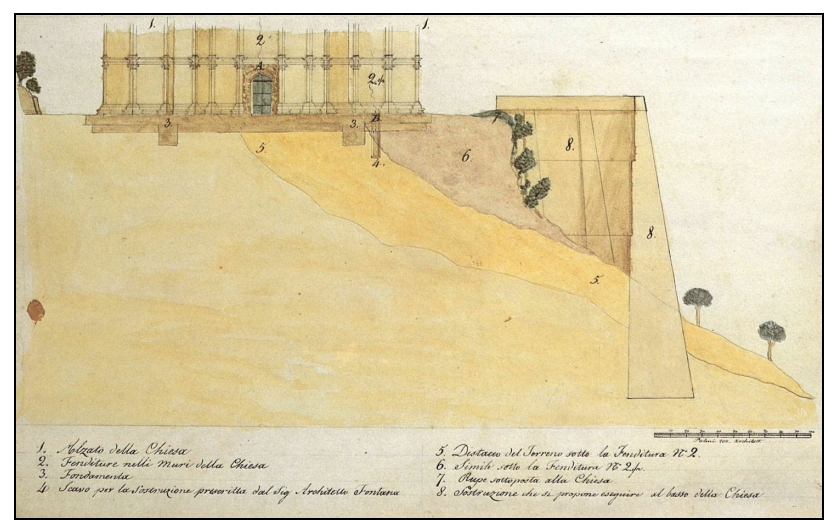

Figure 3

Figures 1-3. Drawings by Angelo Mosconi, 1805. From top: Profile of the slope were the church is built - Prospect from south with the left half of the designed wall - Prospect from west and section of the designed wall

Figure 2 (Tav. IV in the original drawing) shows a view of the church along the west-east direction and the land around. The main vertical cracks observed on the structural walls are also shown. A half of the new massive wall is represented on the left side while the right side shows the existing situation with a view of the scarp.

Similarly, in Figure 3, the west façade of the church is represented showing the existing vertical cracks in the tribune. The drawing clearly depicts a subsoil region probably involved in a sliding mechanism, described as a distacco del terreno sotto la fenditura $n .2$. The section of the massive wall architect
Fontana proposed to build in order to retain the soil is represented in Figure 3 with number 8 (number 2 in Figure 2). Also, the drawing shows a vertical wall to be built underneath the south tribuna, next to the existing foundations (number 4).

The proposal of countermeasures consisting of underpinning beneath the southern apse and of a large polygonal retaining wall appeared to be a valid solution to be pursued. In 1839 Luigi Poletti led to the completion of the construction of a semi-circular gravity retaining wall with niches (Vaccari, 1991, pp. 152-155).

Following the 1915 earthquake, the cracks in the walls of the Tempio della Consolazione increased. Soil investigations were then carried out (Conti, 2004). In 1926, after serious damage, the eastern apse underwent consolidation work, consisting mainly of underpinning of the southeastern pilaster (Mariani, 2008). A Technical-Scientific Committee was formed in 1953, with the aim of investigating the causes which originated a large crack along the median of the semi-cupola above the eastern section, and the consequent damage to the external walls. The resulting consolidation work mainly consisted of the injection of a cement-like mixture into the foundations (about 300 tons) and a diaphragm wall above the church was built (Conti, 2004, p. 104).

Once again the church did not reach the condition of stability. New cracks in the east and west tribune had opened. In 1983 a new campaign of investigations was undertaken, i.e. field investigations and topographic measurements. The findings put into question the effectiveness of the previous intervention of grout injection, which had considerably overloaded the structure (Conti, 2004).

Finally, structural and geotechnical countermeasures have been undertaken more recently (1990s), consisting in underpinning (micropiles all around the existing foundations), diaphragm walls made of large piles and structural reinforcement (Mariani, 2006, 2008. Fig. 4).

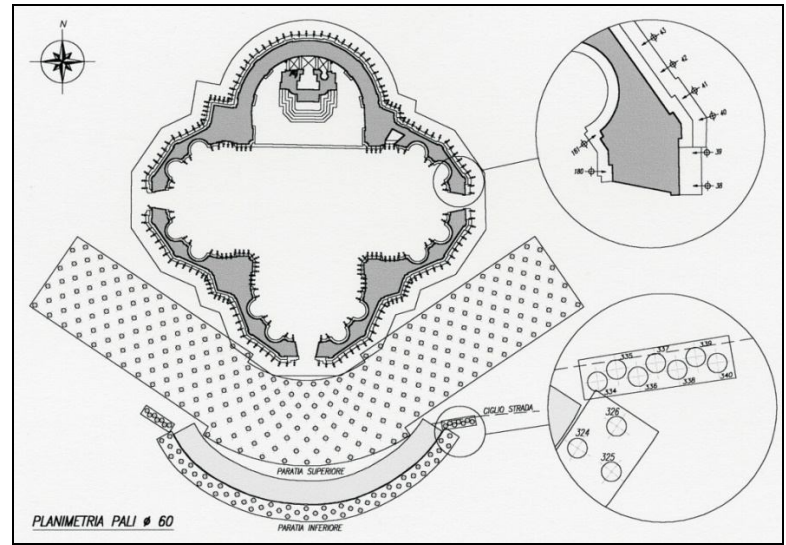

Figure 4. Recent interventions (Mariani, 2006 and 2008)

In the diagnosis and in the interventions of the twentieth century we can observe a difficulty of interpretation, invoking different causes responsible for the observed damage, which can be reasonably attributable to differential settlements at the foundation level, presumably derived from the soil heterogeneity of the deposits characterized by different stiffness and strength (Giani et al., 1997), to seismic actions induced by frequent earthquakes occurring over the centuries, to sliding mechanisms from north to south involving the soil region underneath the church and the retaining wall (Mariani, 2008). 
The new results provided by the geomatic survey of the Tempio della Consolazione point out that the entire body of the church, made up of the four tribune leaning against the central volume crowned by the drum and dome, is uniformly off plumb as if it were a tower. This is an extremely important information that can lead to more detailed diagnosis. A similar pattern of deformation may have resulted in the breakage of tie beams without seriously damaging the wall parts, which show a remarkable structural efficiency.

Also, the evidence of a rotation-type mechanism as a rigid body may pose the basis for an improved knowledge of the geotechnical aspects connected with the observed damage. Based on the scenario now revealed by the present study, it would maybe appropriate to reconsider the effectiveness of the countermeasures adopted through the recent decades which involved the entire building and, rather, tend toward a finalized intervention at the south side of the church.

In restoration, too often the interventions are transformed into an exercise of refined technological solutions, which have little to do with a proper relationship between knowledge, diagnosis and design. This is an unavoidable premise for a scientific method of architecture restoration.

\section{SURVEY WITH GEOMATIC TECHNIQUES}

Since the objective of this research was to highlight the deformations of the entire church, it was performed a comprehensive study for an accurate geometrical description of the Tempio using integrated geomatic techniques. The aim was to evaluate both the overall configuration (global spatial attitude) and that of single elements (inclination of pillars and cornices, internal and external crack pattern on walls and domes).

The geomatic methodologies utilised include: static and kinematic GNSS for georeferencing the monument and the surrounding ground in a global datum (ETRF2000); internal and external laser scans for an overall geometric reconstruction; digital photogrammetry for the integration of the scans with colours and the coverage of some shadow areas; high-precision geometric leveling for an accurate measure of the slope of the monument base; high precision total stations for the alignment of the laser scans and a 3D survey of the crack pattern and the local geometry of single elements.

More information on the application of geomatic techniques to the cultural heritage survey and 3D reconstruction can be found on Bitelli (2002), Fai et al. (2011), Balletti and Guerra (2015), Tucci and Bonora (2015), Tommasi et al. (2016).

More details, drawings and tables concerning the geomatic survey of the Tempio are present in Brizioli (2015) and Bisciotti (2016).

\subsection{GNSS, Total Station and Leveling}

By means of GNSS techniques (static and NRTK) and a total station was determined a 3D geodetic reference network at a centimeter level accuracy, including vertices external and internal to the monument. The network adjustment was computed in the UTM/ETRF200 datum, so as to georeference the whole survey in a global datum. Total station 3D measurements and precision geometric leveling were then utilised to identify the deviations of architectural elements from horizontal or vertical planes/lines, and to survey the crack pattern accurately.
The instruments used were two Topcon geodetic GNSS receivers GR-3, a Leica TS06 total station and a Leica NA3000 digital level with calibrated invar rods.

With the total station the "nominally" horizontal elements (floor, outer base seat, internal cornices at different levels) were accurately measured, computing the vertical deviations of significant points from a standard horizontal plane. For each group of points (e.g. the first level cornice) was then determined a mean interpolating plane and its maximum slope direction. For the vertical elements (e.g. the four pillars under the dome) were measured the deviations from the plumb line in the north and east components. The results were then compared with each other in order to verify that there were no geometrical inconsistencies in the individual elements and in their relations.

The GNSS technique was utilised, beside the reference network, for surveying the main points of the base perimeter and the area surrounding the Temple.

The precision leveling technique was utilised for a more accurate measure of the vertical displacements with respect to a horizontal plane for the external outer seat at the base of the building. The results show that the base is inclined along an approximately north-south direction, presenting a $37.7 \mathrm{~cm}$ lowering toward north (Figg. 5-6 and Tab. 1).

\subsection{Horizontal architectural elements}

Figure 5 shows the location of some architectural elements measured and analysed. Internally, the measures interested the cornices at different altitudes and the floor. The cornice $\mathrm{V}$ (lantern base) was excluded from the final analysis because the total station measures were very inclined, thus with a lesser accuracy with respect to the others.

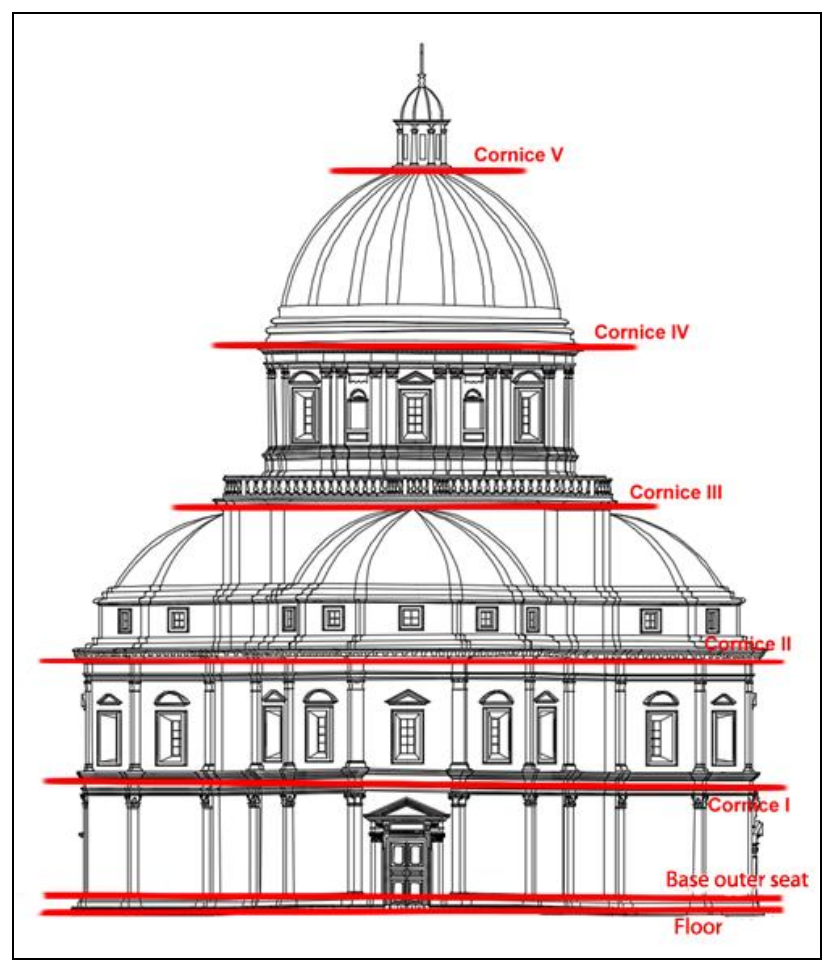

Figure 5. Location of some architectural elements

For each element was computed the height difference $\Delta \mathrm{z}$ between the highest and the lowest point (Tab. 1). 


\begin{tabular}{|c|c|c|c|c|c|c|}
\hline & $\frac{\dot{0}}{\underline{I}}$ & 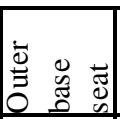 & $\begin{array}{l}0.0 \\
.0 \\
0 \\
0\end{array}$ & $\begin{array}{l}0 \\
.0 \\
0 \\
0 \\
ن\end{array}$ & 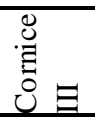 & $\begin{array}{l}\stackrel{0}{0} \\
\Xi \\
0 \\
0\end{array}$ \\
\hline $\mathrm{z}(\mathrm{n}$ & -0.375 & -0.377 & -0.385 & -0.480 & -0.209 & -0.233 \\
\hline$\alpha\left(^{\circ}\right)$ & $0.575^{\circ}$ & $0.515^{\circ}$ & $0.600^{\circ}$ & $0.669^{\circ}$ & $0.686^{\circ}$ & $0.864^{\circ}$ \\
\hline
\end{tabular}

Table 1. Maximum height differences and inclination angles

By means of a procedure included in the Leica Cyclone software (also used for the laser scanning analysis, see Par. 2.4), interpolating planes were computed for the various levels of Fig. 5, determining for each one the line of maximum slope and its inclination angle $\alpha$ from the horizontal direction (Tab. 1). For the cornice I, due to an architectural discontinuity, the points in the altar area and those in the remaining part of the church were analyzed separately. Table 1 shows the mean value of $\alpha$.

Figure 6 shows the maximum slope directions obtained for the various architectural elements, overlapping in a single plan: it can be seen, the higher the element altitude, the line tends to rotate slightly clockwise, thus putting into evidence a torsional deformation of the church.

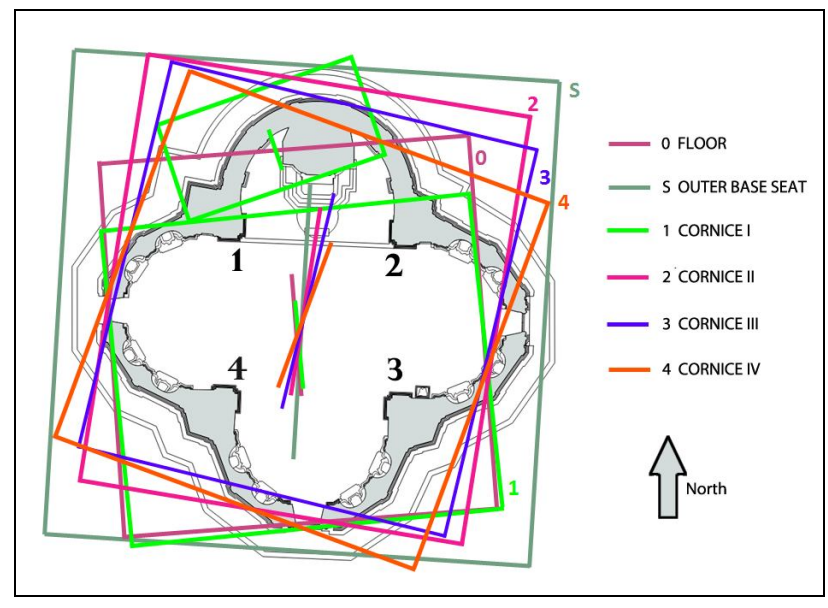

Figure 6. Superimposition of the maximum slope directions for architectural elements at different levels (ref. Fig. 5)

\subsection{Dome pillars inclination}

For an accurate assessment of the pillar inclination with respect to the vertical direction, the $3 \mathrm{D}$ coordinates of a number of points along the central edge of each column were determined by means of the total station. For each point (Fig. 3 ) were determined the eastern and northern components $f_{N}$ and $f_{E}$ of the horizontal distance $f$ from an ideal plumb line starting at the highest point of the edge, related as follows:

$$
f=\sqrt{f_{N}^{2}+f_{E}^{2}}
$$

Table 2 shows the values of the off plumb (north and east components) from top to base for each pillar. In Fig. 7 the total off plumb of the four pillars was plotted in planimetry. It is clear as the vertical elements are inclined toward the north (altar area); such results are concordant with the slopes measured for the horizontal architectural elements.

\begin{tabular}{|c|c|c|c|}
\hline$\vec{\Xi}$ & $\underset{\Xi}{\Xi}$ & $\underset{\Xi}{\Xi}$ & $\underset{\Psi}{\Xi}$ \\
\hline 1 & 0.127 & 0.055 & 0.138 \\
\hline 2 & 0.143 & 0.003 & 0.143 \\
\hline 3 & 0.175 & -0.024 & 0.177 \\
\hline 4 & 0.169 & 0.036 & 0.173 \\
\hline
\end{tabular}

Table 2. Off plumb values for the four dome pillars

Figure 7 also shows a comparison between the present pillar inclination with the values found in 1987 (Mariani, 2008): we can see that the situation has remained largely unchanged over the last 28 years.

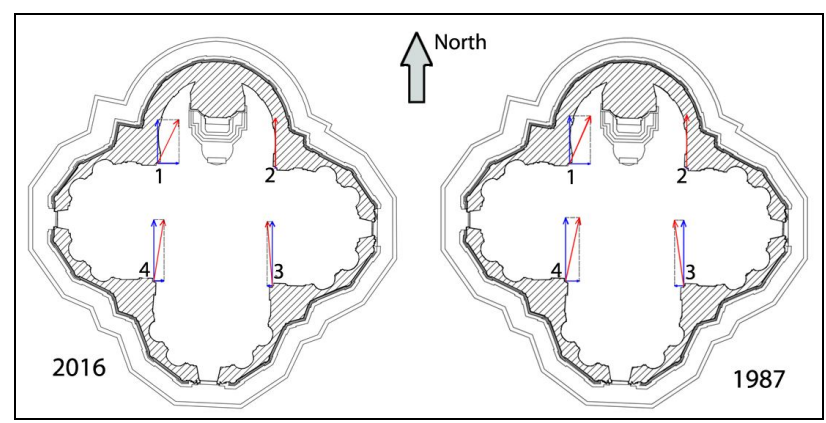

Figure 7. 1987-2016 comparison of the pillars off plumb

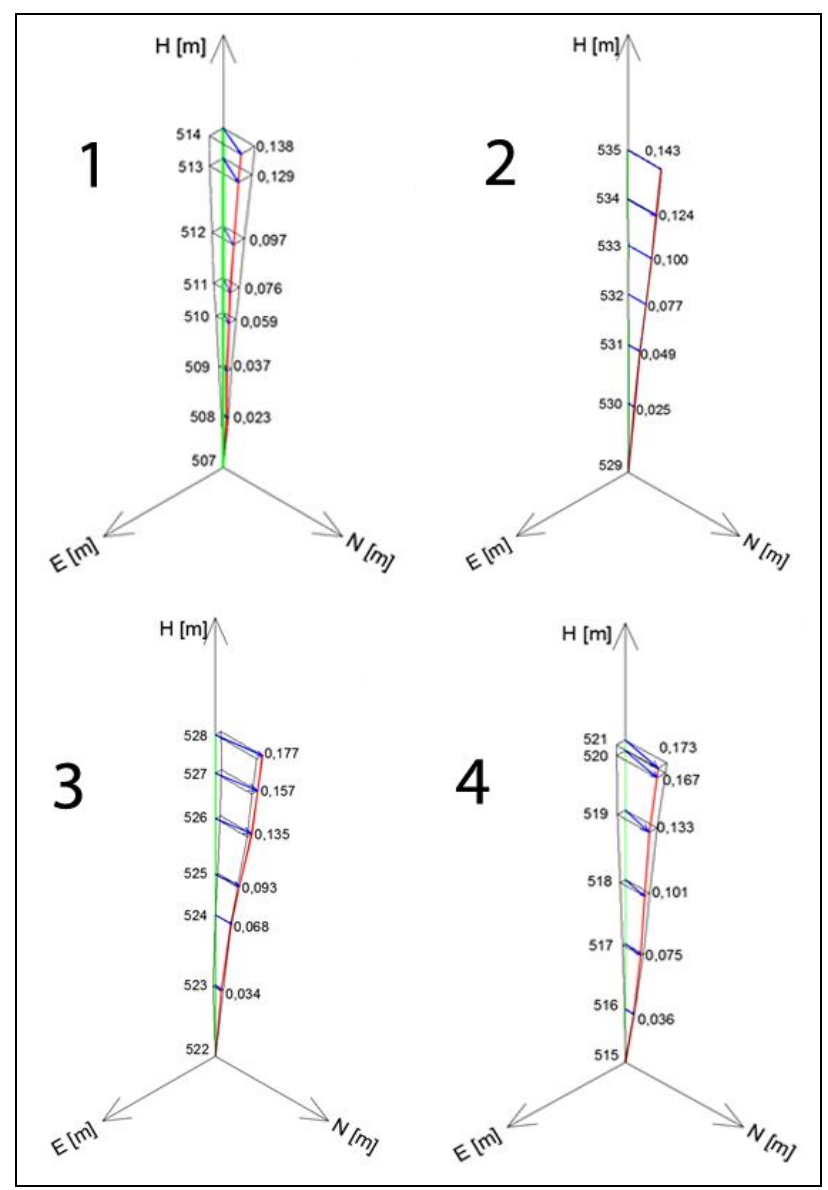

Figure 8. Axonometric representation of the pillars off plumb (amplificated by a factor of 10) 
Figure 8 contains an axonometric representation of the off plumb measured along the four pillars, amplificated by a factor of 10. For each one, the red line corresponds the actual edge, while the green one is the vertical. These results were confirmed by analyzing the same elements from the cloud of laser points (see Par. 2.4).

\subsection{Laser scanning}

In the time span from 2011 to 2015 were carried out different laser scanning surveys outside and inside the Tempio, using both phase difference and flight time scanners. Four instruments were utilised: a Leica C10 (external/internal scans 2011), a Leica HDS6000 (internal scans 2011), a Riegl LMSZ420i (external scans 2014) and a Faro Focus 3D X130 (internal scans 2016).

The point clouds acquired with different scanners have been oriented with respect to each other and in the global datum by means of appropriate targets (opaque for the Faro instruments, reflective for the others) whose 3D coordinates were determined by GNSS/Total Station measures (Par. 2.1). All scans were aligned to form a single $3 \mathrm{D}$ model comprising the interior and the exterior of the monument through the Leica Cyclone software.

Thereafter, to the cloud points were associated the RGB colour values deriving from digital photographs acquired with high resolution cameras: for the 2014 surveys a Nikon D200 on a calibrated mount on top of the Riegl scanner; for the 2016 campaign, a Nikon D800E and the digital camera included in the Faro scanner. The RGB colours "paint" the point cloud obtaining a realistic view (Fig. 9).

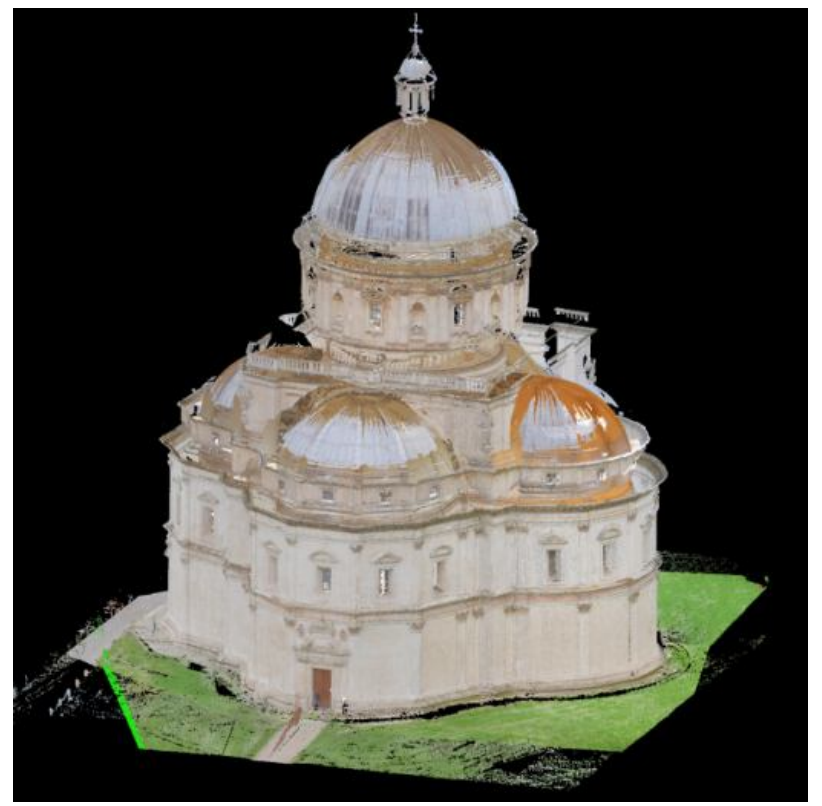

Figure 9. Point cloud assembled and coloured

The scans were carried out by placing the laser on appropriate points so as to minimize the shadow areas. With the Faro instrument, which is very compact in size, an internal scan was carried out from the cornice just below the dome. Never before a scan had been performed from this position (Fig. 10).

For the church floor, more than 800 points were extracted from the point cloud creating a contour lines model with a $2 \mathrm{~cm}$ interval. From such model, the floor shows a lowering of about
$0.375 \mathrm{~m}$ in the north-south direction (toward the altar area), confirming what previously obtained from the total station survey (Par. 2.1). Measuring coordinates on various architectural elements (cornices, pillars, ...) from the 3D point cloud by means of the Cyclone software were obtained values matching at one centimeter level those deriving from the direct survey described in Par. 2.1.

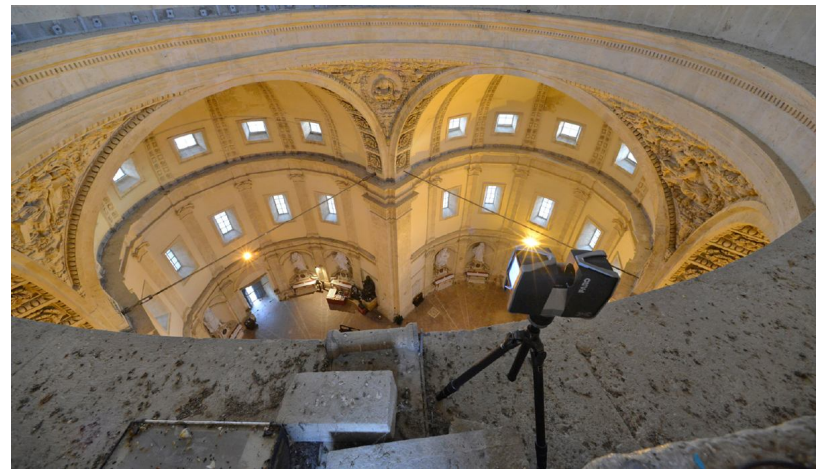

Figure 10. Internal scan from the dome base

\subsection{Crack pattern and moisture}

To analyze in depth the crack pattern, with the total station (in reflectorless mode) were measured 438 points along the visible cracks. Their coordinates were imported into the Cyclone software, thus tracing the crack lines on the 3D point cloud. The cracks were divided into three categories: open, stuccoed (still visible and measured) and stuccoed ones that have reopened.

It was observed as cracks are absent on the four central pillars, while they are present in all four apses, with a prevalence in the east-west half domes. The cracks are characterized, however, by a modest thickness, always less than $1 \mathrm{~cm}$. Of particular note is the presence of a recent crack through the north-east apse eastern sector. Externally have been found some cracks on the walls of the apses, except the north one, and no one on the corner pillars, the drum and the terrace.

On the point cloud were also traced the crack lines derived from a previous study (Masciarelli, 1988-89), so that a comparison with the current state can be made. From the Masciarelli survey can be seen that in 1989 internal cracks did not show on the pillars (but some external ones), while there were cracks interesting the apses walls (except for the north one), with a pattern somewhere slightly different from the present. Comparing the two surveys, it can be noted as in 1989 passing cracks were numerically more than presently. Moreover, while nowadays there is a preferential axis of development of damage (east-west), in the Masciarelli the cracks were equally distributed over all the apses except for the north one.

Thanks to post processing application of colour to the point cloud, it was finally possible to determine the status of the moisture spots at the intrados of the central dome and the apses semi-domes, and compare the 2016 and 2011 patterns. From the comparison (Fig.11), it is evident how the spots are considerably enlarged, especially the patches that affect the central dome, the north and east apses, and also some of new formation (north and west apses).

It has to be noted that the lead covering of the apses halfdomes has been restored in 2016, so any rain infiltration should now be eliminated. 


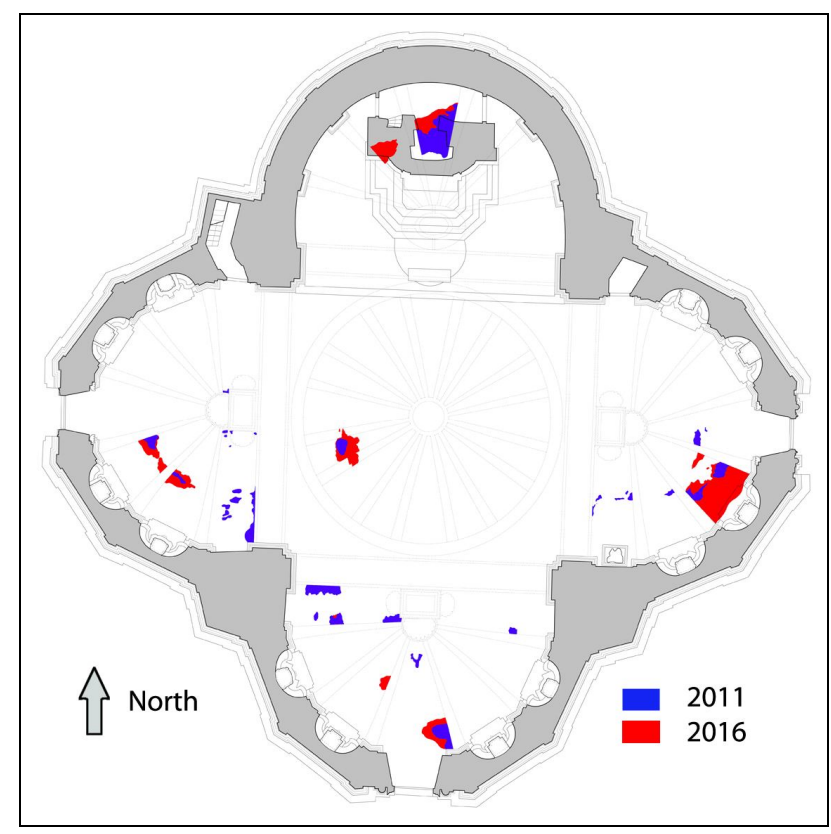

Figure 11. Moisture patches on the dome intrados

\subsection{Overall attitude and deformation}

From the 3D metric point cloud generated by the laser scans and their elaboration, it has been possible to analyze the overall attitude of the monument and its deformations with respect to an "ideal" shape and orientation with a vertical central axis.

A starting point has been the determination of the offset between the dome center (lantern) vertical projection and the geometrical center of the floor. The resulting offset is $41.6 \mathrm{~cm}$ (north) and $16.2 \mathrm{~cm}$ (east) with a resultant of $44.7 \mathrm{~cm}$ (Fig. 12). Confirming the results obtained from total station and leveling (Par. 2.1, Tab. 1), the angle of inclination of the church determined from the model section is about $0.45^{\circ}$ toward north (Fig.13).

All the architectural elements of the church show a similar northward rotation: for the horizontal elements (cornices, floor, base seat) the angle of inclination is between $0.5^{\circ}$ and $0.9^{\circ}$ while for vertical elements (walls and pillars) the angle of rotation is between $0.6^{\circ}$ and $1^{\circ}$. Summarizing, all measures and the $3 \mathrm{D}$ reconstruction show that the church has undergone an overall rotation leaning towards the north.

Finally, it has also been analyzed whether, following the displacements suffered by the church, there has been any dependent deformations of the arches supporting the dome and the drum horizontal section, in addition to those relating to the off plumb of the pillars.

Comparing the current profiles of the arches and the circumferences which theoretically approximate their initial configuration, it can be noted that due to the dome load the arches had undergone a slight lowering on the center and expansion of the haunches. Anyway, data obtained fall well within the range of values considered acceptable at the time of the church edification. It can be concluded that no significant deformations are evidenced on the arches.

Even for the drum has been defined a perfect circle, hypothetical initial geometry, tangent in two diametral points to the horizontal section of the terrace floor level and windows.

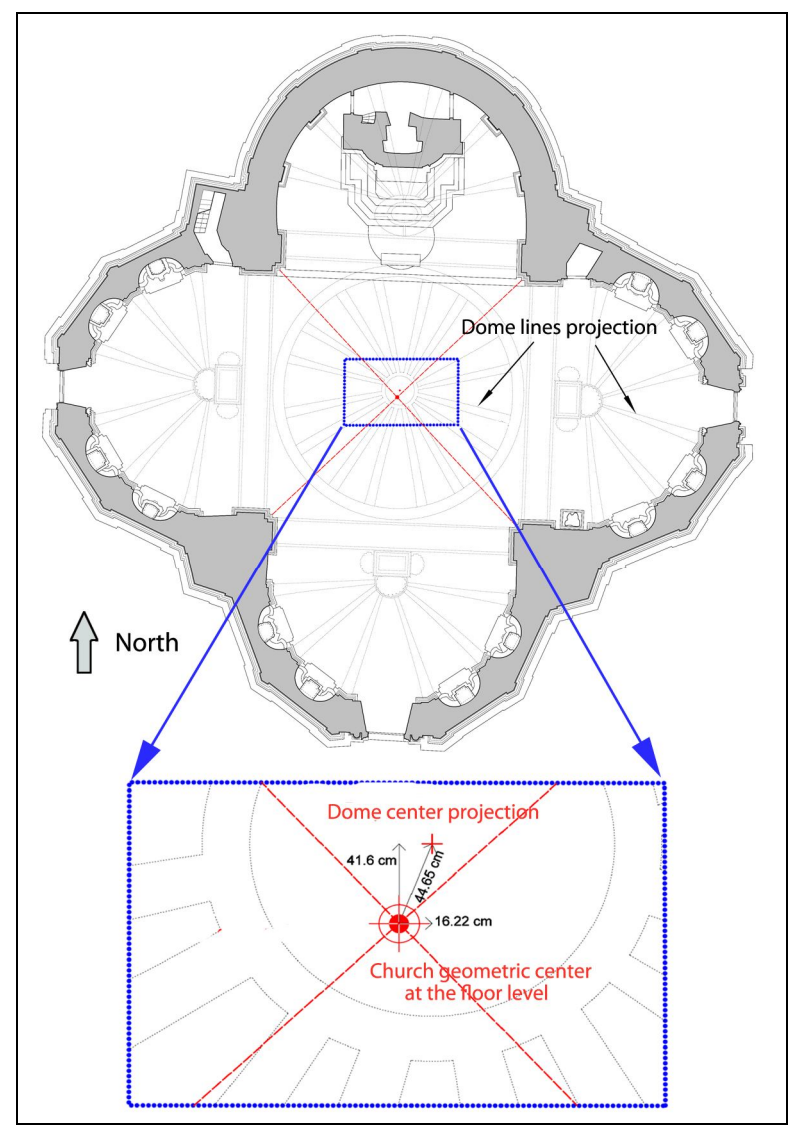

Figure 12. Vertical projection of the dome center on the floor

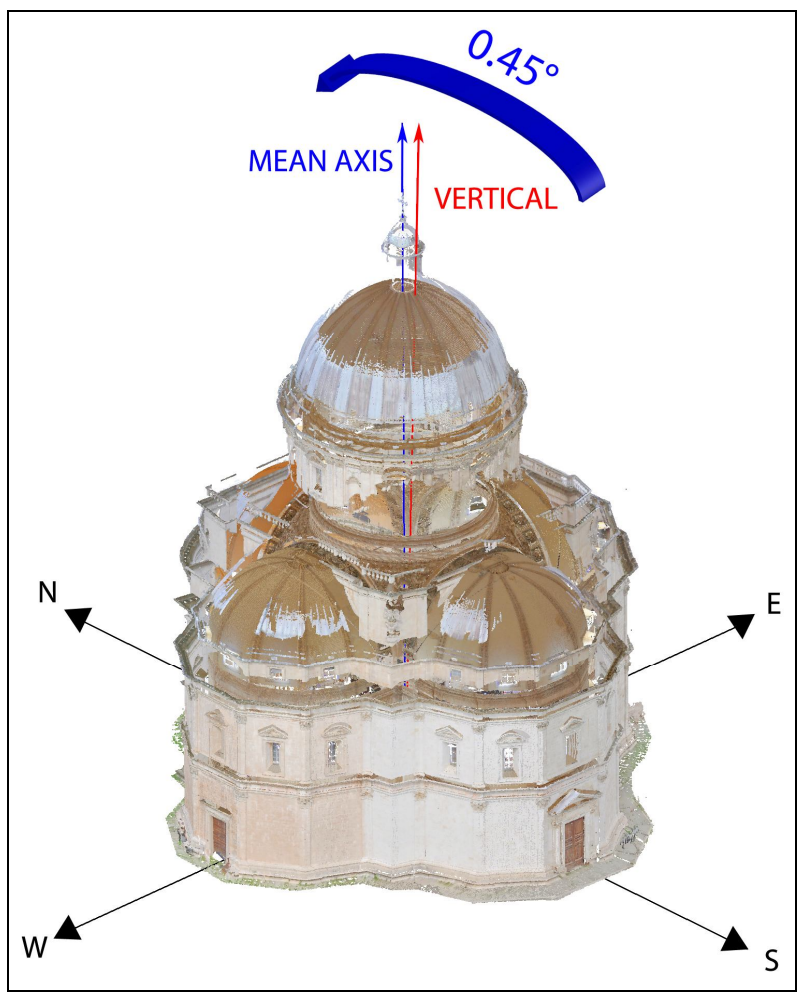

Figure 13. Overall rotation of the monument

Comparing such circle with the measured geometry, the differences show very modest values $(2-3 \mathrm{~cm})$, falling within the constructive tolerances. Even in this case, it can be 
affirmed that the drum has not undergone any significant deformation.

The above considerations and the fact of having identified, effectively, a single direction of inclination, lead to believe that the temple has substantially expressed a behaviour similar to that of a rigid body, undergoing a rotation toward the north side (Fig. 13), and that the movement has occurred for its maximum part after the building completion.

\section{GEOTECHNICAL ASPECTS}

As clearly emphasized in a comprehensive paper by Calabresi (Kerisel Lecture, 2013) “...there is a long list of monumental buildings that, owing to the slow or very slow displacements in the foundation planes, suffer progressive instability. In these cases a conflict sets in between the purely technological approach (aimed at reinstating the safety of the monument with structural interventions which, while ensuring that the external aspects are preserved, modify the original structural design), and a softer approach, on the other hand, that begins with a study of the phenomena underlying the instability and makes a long and perhaps uneventful search of the causes that need to be removed to stop the instability and if possible save the monument without substantial alterations so as to respect its historic integrity. It is worth recalling that the search for the causes is always a time-consuming exercise that is often much more expensive than ordinary, obvious structural and geotechnical engineering interventions."

A systematic study of the saving projects carried out in Italy (until 1995) and including thirty-four buildings of different kinds with regard to style, age, use, shape and dimensions has shown that structural strengthening together with underpinning by micropiles have been the largely predominant type of measure (Fig. 14c). The adoption of micropiles is taken whenever cracks or settlements are observed, although the causes of damage maybe very different from case to case. (Cecconi et al., 1997). The Tempio of S. Maria della Consolazione in Todi is among the monuments included in this cited previous study, where the observed damage (cracks, settlements) are mainly associated to possible causes such as slope instability and soil heterogeneity (i.e.: original defects). At present, this scenario could be updated for the case at hand by including rotation among the observed damage. With regard to the preservation measures, by accounting on published data, Cecconi et al. (1997) identified structural strengthening among the most significant ones. In fact, as already mentioned in the previous paragraphs, structural and geotechnical countermeasures have been undertaken recently, consisting in underpinning, diaphragm walls made of large piles and structural reinforcement (Mariani, 2006, 2008).

From a geological/geotechnical point of view the hill of the city of Todi is made up of clastic sediments in lacustrine and fluvial-lacustrine facies, from basal clays to conglomerates at the top (Cencetti et al., 2005). Based on the information gained from the geological data relative to two borings, S20, S21 (http://dati.umbria.it/dataset/banca-dati-indagini-geognostichegeo-fisiche) and those reported by Giani et al. (1988), Figure 15 shows a section of the soil profile along the N-S direction. The dashed line represents the trace of a sliding surface documented in Mariani (2006). The main countermeasures adopted in recent years are not represented in this Figure (Mariani, 2006, 2008).

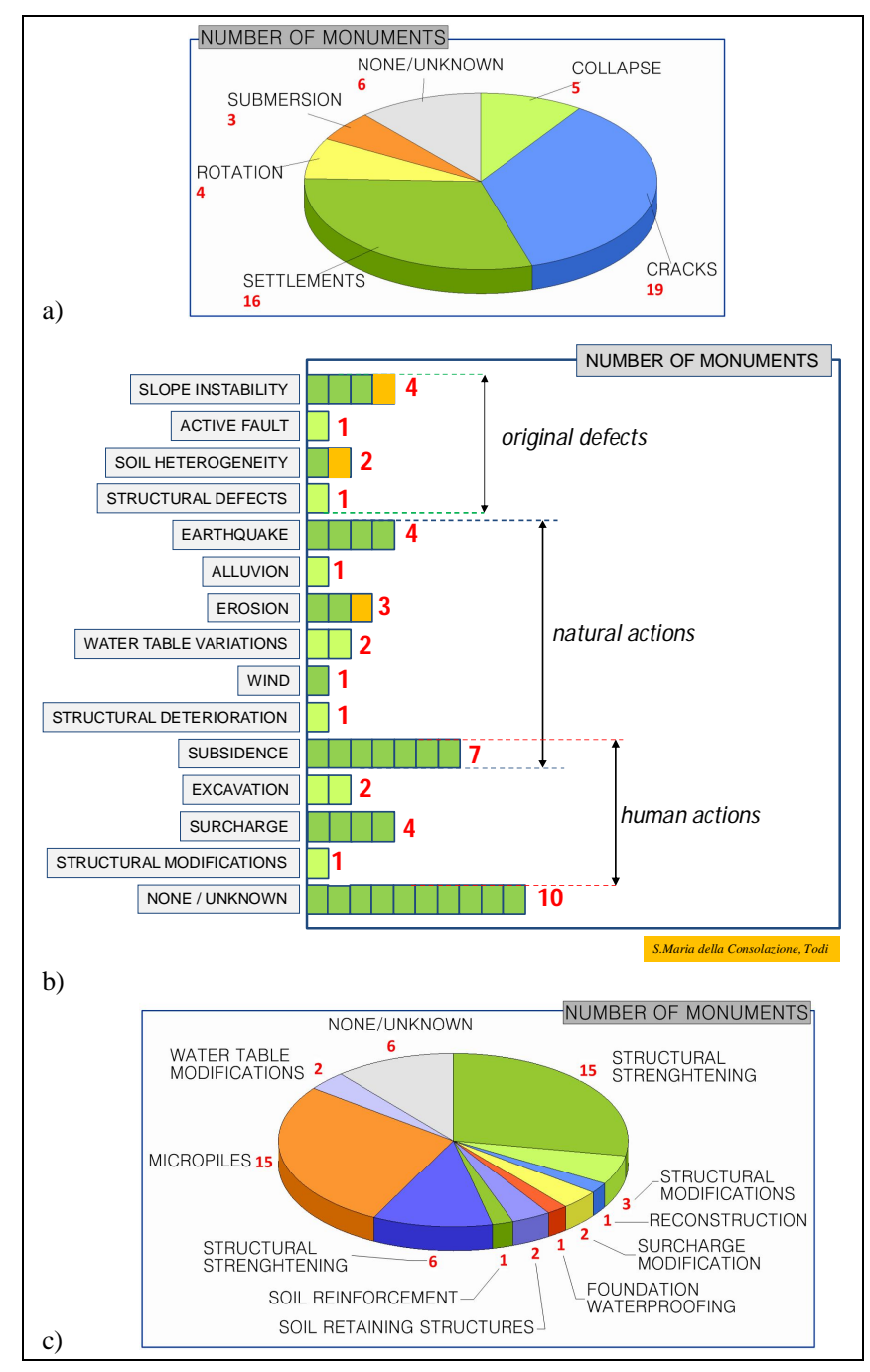

Figure 14. Analysis of some Italian monuments (modified from Cecconi et al. 1997): a) damage types; b) possible causes of damage; c) preservation measures.

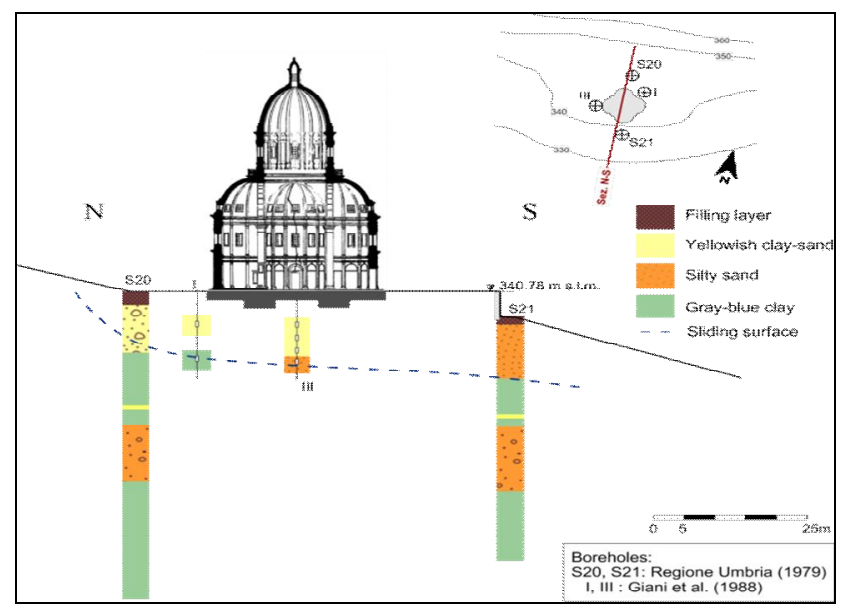

Figure 15. Soil profile from previous in-situ investigation.

As a first attempt to capture the measured rotation $\alpha$ along the main axis $\left(\alpha \cong 0.5^{\circ}\right.$ ), which is consistent with the total settlement $(\mathrm{w}=0.375 \mathrm{~m})$ measured at the north side, along the direction $\mathrm{N}-\mathrm{S}$, the rotational stiffness of the soil-foundation system has been introduced ( $\mathrm{K}_{\theta}$, Tab. 3). Although the subsoil 
is rather heterogeneous, an average soil stiffness $(E=4 \mathrm{MPa}$, see Tab. 3) has been adopted as a first attempt.

\begin{tabular}{|c|c|}
\hline$K_{\theta}=\frac{4}{3} \frac{E a^{3}}{1-v^{2}}$ & $\begin{array}{l}\text { E: elasticity modulus (soil) } \\
\vee: \text { Poisson coefficient (soil) } \\
\text { a: radius }\end{array}$ \\
\hline $\begin{aligned} & \text { assumed value } \\
& E=2.5 \mathrm{MP} \\
& E=5.0 \mathrm{MP} \\
& E=13 \mathrm{MPa} \\
& \mathrm{v}=0.25 \\
& a=21.5 \mathrm{~m} \\
& N \text { : total wei }\end{aligned}$ & $\begin{array}{l}\left.\begin{array}{l}\text { silty sand) } \\
\text { yellowish clay) } \\
\text { say-blue clay) }\end{array}\right\} \text { (Giani et al. 1988) } \\
t \text { of the building }=170 \mathrm{MN} \quad \text { (Maria }\end{array}$ \\
\hline
\end{tabular}

Table 3. Rotational stiffness $K_{\theta}$ of a circular rigid foundation resting on a semi-infinite homogeneous elastic soil deposit (Bowles, 2001)

In this simple assumption and by imposing that rotation $\alpha$ towards the north is only due to gravity load (= 170MN) eccentricity, it can be inferred that gravity load at the foundation level should have an eccentricity of about $1.4 \mathrm{~m}$ with respect to the centre of gravity.

Lower values of eccentricity could be attained by relying upon a higher deformability of the foundation soils.

\section{FINAL REMARKS}

The geomatic survey, completely processed until the production of CAD drawings (plans, sections and elevations), revealed for the first time the entity and the singularity of the subsidence phenomena that have affected the Tempio della Consolazione. These new data, integrated with a historical research, help to clarify when the deformations occurred over the building phases of the Temple.

A more detailed knowledge of the structural behaviour contribute to obtain a more significant "structural diagnosis", from which can be derived proposals for interventions appropriate to the nature of the problem. The geometric and geotechnical analysis also allow to plan further possible investigations or reflections on the plausible deformation mechanism of the whole system structure/foundations/subsoil in which the Consolazione arose.

The survey data acquired also provide an effective starting point to check possible future deformations of the complex, whose control should be hopefully entrusted to a specific and accurate monitoring system.

\section{ACKNOWLEDGEMENTS}

We thank Dr. Eng. Gino Centi for his support to the 2011 and 2014 surveys.

\section{REFERENCES}

Masciarelli F., 1989. Analisi strutturale della chiesa di Santa Maria della Consolazione in Todi, Graduation Diss., Università degli Studi di Firenze, Facoltà di Architettura, A.A. 1988-1989. Supervisor: Di Pasquale S.

Giani G.P, Del Greco O., Astori B., Rossi P.P., 1988. Analysis and control of the static behaviour of the Consolazione Church in Todi, Italy. Proc. of the International Symposium The Engineering Geology of Ancient Works, Monument and Historical Sites, Athens. Reprinted by ISMES S.p.a., Bergamo.

Bentivoglio E., 1991. Una fabbrica tante storie, in Il tempio della Consolazione a Todi, edited by Bruschi A., Milano, pp.76-87.
Comez G., 1991a. I restauri dalla fine del XVIII secolo ad oggi, in Il tempio della Consolazione a Todi, edited by Bruschi A., Milano. Comez G., 1991b. Il tempio nella storia religiosa e civile della città, in $I l$ tempio della Consolazione a Todi, edited by Bruschi A., Milano.

Vaccari M., 1991. L'architetto Luigi Poletti di Modena, il tempio della Consolazione e le rovine della Piana 1829-1845, in Il tempio della Consolazione a Todi, edited by Bruschi A., Milano.

Bruschi A., 1994. Santa Maria della Consolazione a Todi. I progetti, l'esecuzione, il modello. In La rappresentazione dell'architettura, a cura di Millon H., Magnago Lampugnani V., Milano.

Cecconi M., D’Amelio, MG., Croce, P., 1997. Comparative analysis of some Italian monuments. Proc. Int. Symposium on Geotechnical Engineering for the Preservation of Monuments and Historic Sites. 6980 C. Viggiani Ed., A.A.Balkema, Rotterdam.

Giani G.P., Ferrero, AM., 1997. Stability analysis of ancient monuments by tridimensional numerical models. Proc. Int. Symposium on Geotechnical Engineering for the Preservation of Monuments and Historic Sites. 175-183 C. Viggiani Ed., A.A.Balkema, Rotterdam.

Bitelli G., 2002. Moderne tecniche e strumentazioni per il rilievo dei beni culturali. Relazione invitata VI Conferenza Nazionale ASITA. Atti VI Conferenza Nazionale ASITA, IX-XXIV, Perugia.

Bowles, 2001. Foundation Analysis and Design. V ed., Mc Graw-Hill Int.

Conti I., 2004. Santa Maria della Consolazione in Todi: gli interventi di restauro architettonico dal 1611 ad oggi, Graduation Diss., Università degli Studi della Tuscia di Viterbo. Supervisor: Gizzi S.

Cencetti C., Conversini, P., Tacconi, P., 2005. The Hill of Todi (Umbria, Central Italy). Giornale di Geologia Applicata 1 (2005) $113-121$.

Mariani M., 2006. Trattato sul consolidamento e restauro degli edifici in muratura - Vol. 1. Dei, Tipografia del Genio Civile, Roma.

Mariani M., 2008. Structural consolidation methods for the Temple of Santa Maria della Consolazione in Todi (Perugia, Italy), damages by landslides and earthquakes, Structural Analysis of Historic Construction: Preserving Safety and Significance, Two Volume Set. Jun 2008, Editors Dina D'Ayala and Enrico Fodde, Taylor \& Francis Group, London, vol. 2, pg. $1123-1131$.

Fai S., Graham K., Duckworth T., Wood N., Attar R., 2011. Building Information Modeling and Heritage Documentation. Proc. XXIIIrd International CIPA Symposium, Prague.

Calabresi G., 2013. The role of Geotechnical Engineers in saving monuments and historic sites. Kerisel Lecture. Proc. of the 18th International Conference on Soil Mechanics and Geotechnical Engineering, 71-83, Paris.

Balletti C., Guerra F., 2015. The survey of cultural heritage. A long story. Rend. Fis. Acc. Lincei (2015) 26(Suppl 1): 115.

Brizioli S., 2014. Indagini metrico-storiche per la conservazione di beni architettonici: Il Tempio della Consolazione di Todi. Graduation Diss., Università degli Studi di Perugia. Supervisor: Stoppini A., Matracchi P., Radicioni F., Brigante R..

Tucci G., Bonora V., 2015. Geomatics and management of at-risk cultural heritage. Rend. Fis. Acc. Lincei (2015) 26 (suppl. 1): 105.

Tommasi C., Achille C., Fassi F., 2016. From point cloud to BIM: a modelling challenge in the cultural heritage field. The International ISPRS Archives, vol. XLI-B5.

Bisciotti E., 2016. Il Tempio della Consolazione a Todi dopo quattro secoli di restauri: Rilievo 3D dello stato di lesionamento e anamnesi degli interventi. Graduation Diss., Università degli Studi di Perugia. Supervisor: Stoppini A., Matracchi P., Radicioni F.. 